\title{
Effect of the one-carbon unit cycle on overall DNA methylation in children with Down's syndrome
}

\author{
CUI SONG ${ }^{1}$, JINGYI HE ${ }^{1}$, JIE CHEN ${ }^{1}$, YOUXUE LIU ${ }^{1}$, FENG XIONG ${ }^{2}$, YUTIAN WANG ${ }^{2}$ and TINGYU LI $^{1}$ \\ ${ }^{1}$ Children Nutrition Research Center, Ministry of Education Key Laboratory of Child Development and Disorders, \\ Key Laboratory of Pediatrics in Chongqing, CSTC2009 CA5002, \\ Chongqing International Science and Technology Cooperation Center for Child Development and Disorders, \\ Children's Hospital of Chongqing Medical University; ${ }^{2}$ Institute of Pediatrics, \\ Children's Hospital of Chongqing Medical University, Chongqing 400014, P.R. China
}

Received December 5, 2014; Accepted September 9, 2015

DOI: $10.3892 / \mathrm{mmr} .2015 .4439$

\begin{abstract}
DNA methylation is a major epigenetic mechanism regulating gene expression. In order to analyze the impact of the one-carbon unit cycle on the overall level of DNA methylation in children with Down's syndrome (DS), the levels of indicators associated with the one-carbon unit cycle, including folic acid (FA), vitamin $\mathrm{B}_{12}\left(\mathrm{VB}_{12}\right)$ and homocysteine (Hcy), and the overall DNA methylation level of DS and healthy controls (HCs) were determined in the present study. A total of 36 DS children and 40 age- and gender-matched HCs were included in the present study to determine the levels of FA, $\mathrm{VB}_{12}$, Hcy and overall DNA methylation. The effect of the one-carbon unit cycle on the overall level of DNA methylation within the DS group was analyzed. The results demonstrated that the level of $\mathrm{VB}_{12}$ was decreased $(\mathrm{P}=0.008)$, while the Hcy level was increased $(\mathrm{P}=0.000)$ in $\mathrm{DS}$ patients compared with the HCs. FA and $\mathrm{VB}_{12}$ levels decreased with increasing
\end{abstract}

Correspondence to: Dr Tingyu Li, Children Nutrition Research Center, Ministry of Education Key Laboratory of Child Development and Disorders, Key Laboratory of Pediatrics in Chongqing, CSTC2009 CA5002, Chongqing International Science and Technology Cooperation Center for Child Development and Disorders, Children's Hospital of Chongqing Medical University, 136 Zhongshan ER Road, Chongqing 400014, P.R. China

E-mail: tyli@vip.sina.com

Abbreviations: DS, Down's syndrome; FA, folic acid; $\mathrm{VB}_{12}$, vitamin $\mathrm{B}_{12}$; Hcy, homocysteine; $\mathrm{HCs}$, healthy controls; $\mathrm{AD}$, Alzheimer's disease; SAM, S-adenosylmethionine; DNMTs, DNA methyltransferases; CHCMU, Children's Hospital of Chongqing Medical University; SD, standard deviation; IQI, interquartile interval; C $\beta S$, cystathionine $\beta$-synthase; 5-MTHF, 5-methyltetrahydrofolate; MTHFR, 5,10-methylenetetrahydrofolate reductase; MTRR, methionine synthase reductase; MS, methionine synthase; APP, amyloid precursor protein

Key words: Down's syndrome, one-carbon unit cycle, overall level of DNA methylation, epigenetic mechanism age in DS patients $(\mathrm{P}<0.05)$. DNA hypermethylation and hypomethylation were observed in DS patients with $\mathrm{VB}_{12}$ deficiency and hyperhomocysteinemia, respectively $(\mathrm{P}=0.031$, $\mathrm{P}=0.021)$. Abnormalities in the one-carbon unit cycle tend to worsen with increasing age in DS children. Thus, one-carbon unit cycle-associated alterations in DNA methylation may be important in the neuropathological alterations observed in DS.

\section{Introduction}

Down's syndrome (DS) is one of the most common and well-known of all chromosomal abnormalities and accounts for $\sim 30 \%$ of all moderate-to-severe cases of mental retardation (1). DS affects approximately one in every 600 live births in the United States (2). Postmortem studies have demonstrated that beginning at age 40 , individuals with DS have a significantly higher risk of neuropathological alterations that meet the clinical criteria for Alzheimer's disease (AD) compared with the general population (3). The incidence of $\mathrm{AD}$ in $\mathrm{DS}$ individuals approaches $15 \%$ after age 45 and $76 \%$ by age 65 (4). However, the biological mechanisms responsible for these heightened risks remain to be elucidated.

Folic acid (FA), vitamin $\mathrm{B}_{12}\left(\mathrm{VB}_{12}\right)$ and homocysteine (Hcy) are known biomarkers of the one-carbon unit cycle. FA and $\mathrm{VB}_{12}$ are important in the remethylation of Hcy to form methionine (5). Methionine is an essential amino acid used for protein synthesis or further transformation to S-adenosylmethionine (SAM), which functions as a methyl donor in several methylation pathways, including DNA methylation (Fig. 1) (6). DNA methylation is one of the most important epigenetic mechanisms regulating gene transcription and can result in long-term alterations in cellular function (7). $\mathrm{CpG}$ dinucleotide methylation, which is catalyzed by DNA methyltransferases (DNMTs), disrupts the binding of transcription factors and recruits proteins, termed methyl-CpG binding domain proteins, which are associated with chromatin compaction and gene silencing (8). Previous studies have indicated that overall changes in DNA methylation levels may be involved in nervous system degeneration in DS patients $(9,10)$.

The aim of the present study was to compare the levels of one-carbon unit cycle-associated indicators $\left(\mathrm{FA}, \mathrm{VB}_{12}\right.$ and 
Hcy) in DS patient serum and plasma with those of healthy controls (HCs) and to examine the overall level of DNA methylation in the two groups. The impact of the one-carbon unit cycle on overall levels of DNA methylation was also analyzed in DS children, and preliminary evidence for mechanisms that may be associated with neurodegeneration occurring in children with DS was provided.

\section{Subjects and methods}

Subjects and blood collection. Between July 21, 2013 and May 10, 2014, 36 standard pediatric DS children treated at The Children's Hospital of Chongqing Medical University (CHCMU; Chongqing, China) were enrolled in the present study. All individuals were diagnosed with DS by karyotype analysis of peripheral blood. When standard DS was diagnosed, the following variables were collected: Age, medical history, anthropometric measures and clinical characteristics, including convulsion, cyanosis, strength, pallor, dizziness, bleeding tendency, palpitations, insomnia, decreased heat tolerance, profuse sweating, nervousness, distal tremor, weight loss, diarrhea, hyperdefecation, abdominal distention and recurrent respiratory tract infection. Physical examinations, including somatometry, cardiac examination, respiratory system examination, nervous system examination, thyroid gland and eye examination were performed. In addition, karyotype analysis of peripheral blood and routine blood tests were carried out. These individuals had no complicating medical conditions, including congenital hypothyroidism, gastrointestinal malformations, heart defects, blood diseases, acute respiratory diseases or malnutrition. Individuals found to have the above-mentioned diseases were excluded from the study. A total of 40 ageand gender-matched HCs were recruited from Chongqing's Transportation Bureau Kindergarten (Chongqing, China) and Chongqing Nankai primary school (Chongqing, China), co-operating with the CHCMU. The present study was approved by the ethics committee of CHCMU and informed consent was obtained from the parents of all participants.

Blood samples were collected into drying tubes and EDTA- $\mathrm{K}_{2}$ tubes for serum, plasma and DNA analyses, respectively. The plasma was obtained by centrifuging blood samples at 2,000 $\mathrm{x}$ g for $10 \mathrm{~min}$ within $30 \mathrm{~min}$ of collection. Genomic DNA was extracted from peripheral blood mononuclear cells using a Wizard ${ }^{\circledR}$ Genomic DNA Purification kit (Promega, Madison, WI, USA; cat. no. A1125) according to the manufacturer's instructions. Serum, plasma and DNA samples were stored at $-80^{\circ} \mathrm{C}$ for $<3$ months prior to analysis. The samples were thawed at room temperature prior to analysis.

Determination of serum $F A$ and $V B_{12}$ concentrations. FA serum concentrations were measured using a folic acid assay kit (Siemens, East Walpole, MA, USA) on an ADVIA Centaur CP analyzer (Siemens, Nuremberg, Germany) by direct chemiluminescence according to the manufacturer's instructions. $\mathrm{VB}_{12}$ serum concentrations were measured using a vitamin $\mathrm{B}_{12}$ assay kit (Siemens) on an ADVIA Centaur CP analyzer also by direct chemiluminescence according to the manufacturer's instructions.

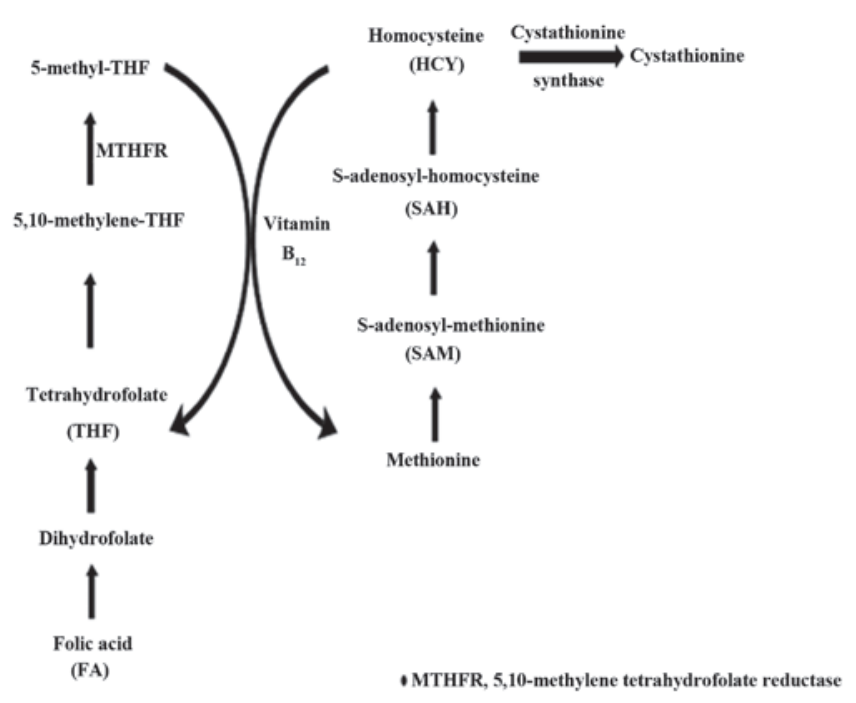

Figure 1. Folate acid metabolism and the one-carbon unit cycle.

Plasma Hcy concentration determination. Plasma Hcy concentrations were measured using an homocysteine detection kit (Meikang Biotechnology Co., Ltd., Ningbo, China) and a Hitachi 7600 Automatic Analyzer (Hitachi High-Technologies Corporation, Tokyo, Japan) for enzymatic cycling assays. Hcy concentrations $>15 \mu \mathrm{mol} / 1$ were considered to indicate hyperhomocysteinemia (11).

DNA methylation determination. Analysis of the absolute quantity of overall DNA methylation was conducted using a MethylFlash Methylated DNA Quantification kit (Colorimetric; Epigentek Inc., Farmingdale, NY, USA; cat.no. P-1034) according to the manufacturer's instructions. Briefly, DNA (100 ng) was bound to strip wells that were specifically treated to have high DNA affinity. The wells were washed with $150 \mu 1$ of the $1 \mathrm{X}$ wash buffer three times and the capture antibody was added. The wells were washed again and then the detection antibody and enhancer solution was added. Color developing solution was added for color development. Finally, the methylated fraction of DNA was quantified colorimetrically by reading the absorbance in a Synergy H1 Multi-Mode microplate reader (BioTek Instruments, Winooski, VT, USA) at $450 \mathrm{~nm}$ within $2 \mathrm{~min}$. The quantity of methylated DNA was proportional to the OD intensity. Absolute overall DNA methylation levels were quantified from a standard curve. The slope of the standard curve was determined using linear regression followed by calculation of the percentage of methylated DNA (5-mC) in total DNA using the following formula (12-14):

$$
5-\mathrm{Mc}(\mathrm{ng})=(\text { sample OD }- \text { ME3 OD) / (slope } \mathrm{x} 2)
$$$$
5-\mathrm{Mc}(\%)=[5-\mathrm{Mc} \text { amount (ng) }] / \mathrm{S} \times 100 \% \text {. }
$$

Statistical analysis. Statistical analyses were performed using SPSS 17.0 (IBM, Armonk, NY, USA). One sample Kolmogorov-Smirnov test was used to evaluate the normality of variable distribution. Values with normal distributions are expressed as the mean \pm standard deviation (SD), while skewed data are expressed as the median [interquartile interval (IQI)]. Comparison among the groups was performed using an independent $\mathrm{t}$-test for values with normal distribution and a 
Table I. Clinical characteristics.

\begin{tabular}{|c|c|c|c|}
\hline Characteristic & DS $(n=36)$ & $\mathrm{HC}(\mathrm{n}=40)$ & P-value \\
\hline Age (years) & $4.87 \pm 1.35$ & $3.96 \pm 0.81$ & 0.550 \\
\hline Gender (male/female) & $13 / 23$ & $16 / 24$ & 0.727 \\
\hline WBC $\left(\times 10^{9} / 1\right)$ & $5.38 \pm 0.73$ & $8.03 \pm 1.23$ & \\
\hline LYM (x109/1) & $2.23 \pm 0.62$ & $2.90 \pm 1.11$ & \\
\hline NEU $\left(\times 10^{9} / 1\right)$ & $2.75 \pm 0.67$ & $4.47 \pm 0.59$ & \\
\hline $\operatorname{RBC}\left(\times 10^{12} / 1\right)$ & $4.44 \pm 0.29$ & $4.94 \pm 0.08$ & \\
\hline $\operatorname{HGB}(\mathrm{g} / \mathrm{l})$ & $135.00 \pm 6.69$ & $130.17 \pm 5.19$ & \\
\hline $\operatorname{PLT}\left(\mathrm{x} 10^{9} / \mathrm{l}\right)$ & $256.83 \pm 51.43$ & $331.50 \pm 103.48$ & \\
\hline
\end{tabular}

Ages are presented as the mean \pm standard deviation. Gender is expressed as the constituent ratio. DS, Down's syndrome; HC, healthy control; WBC, white blood cells; RBC, red blood cells; PLT, platelets; HGB, hemoglobin; LYM, lymphocytes; NEU, neutrophil.

Mann-Whiney U test for skewed variables when appropriate. $\mathrm{P}<0.05$ was considered to indicate a statistically significant difference.

\section{Results}

Clinical characteristics of participating subjects. The clinical characteristics of the subjects at the time of study enrollment are presented in Table I. A total of 36 DS patients (mean age \pm SD: $4.87 \pm 1.35$ years; $63.88 \%$ females) and $40 \mathrm{HCs}$ (mean age \pm SD: $3.96 \pm 0.81$ years; $60 \%$ females) were included in the present study. No significant differences in the age or gender between the two groups were identified $(\mathrm{P}>0.05)$.

Analysis of one-carbon unit cycle biomarkers and DNA methylation. The DS patients had significantly lower $\mathrm{VB}_{12}$ levels (342.55 $\pm 193.01 \mathrm{pmol} / \mathrm{l}$ vs. $447.38 \pm 130.70 \mathrm{pmol} / \mathrm{l}$; $\mathrm{P}=0.008)$, but higher Hcy levels $[8.85$ (6.93-13.3) $\mu \mathrm{mol} / 1 \mathrm{vs}$. $5.20(4.70 \sim 5.88) \mu \mathrm{mol} / 1 ; \mathrm{P}=0.000]$ compared with the $\mathrm{HCs}$, respectively. No significant differences in the serum FA or overall DNA methylation levels were identified between DS patients and $\mathrm{HCs}(\mathrm{P}>0.05$; Table II).

Age subgroup analysis of one-carbon unit cycle biomarkers within DS patients. The level of serum FA in DS patients between 3 and 6 years old was significantly lower than that in patients $\leq 3$ years old $(6.34 \pm 3.20$ vs. $10.62 \pm 3.43 \mathrm{ng} / \mathrm{ml}$, respectively; $\mathrm{P}=0.015)$. In addition, the $\mathrm{FA}$ levels were significantly lower in children $\geq 6$ years old compared with children $\leq 3$ years old $(4.92 \pm 2.34$ vs. $10.62 \pm 3.43 \mathrm{ng} / \mathrm{ml}$, respectively; $\mathrm{P}=0.001)$. No significant differences in FA levels between children in the 3-6 year-old group and the $\geq 6$ year-old group were identified ( $\mathrm{P}=0.272$; Fig. 2). Serum $\mathrm{VB}_{12}$ levels in DS patients $\geq 6$ years of age were significantly lower than those in patients from the 3-6 year-old group and $\leq 3$ years old (222.04 \pm 84.11 vs. $382.21 \pm 244.45$ and $420.23 \pm 172.82 \mathrm{pmol} / \mathrm{l}$; $\mathrm{P}=0.044$ and $\mathrm{P}=0.002$, respectively). No significant difference in serum $\mathrm{VB}_{12}$ levels between the $\leq 3$ year-old group and the 3-6 year-old group was identified ( $P=0.66$; Fig. 2$)$. The plasma Hcy level in DS patients who were $\geq 6$ years old was
$13.08 \pm 8.581 \mu \mathrm{mol} / 1$, which was higher than that in patients from the 3-6 year-old group $(9.99 \pm 3.99 \mu \mathrm{mol} / \mathrm{l})$ and the $\leq 3$ year-old group $(9.89 \pm 5.51 \mu \mathrm{mol} / \mathrm{l})$. However, these differences were not statistically significant $(\mathrm{P}=0.289$ and $\mathrm{P}=0.961$, respectively; Fig. 2).

Impact of one-carbon unit cycle on DNA methylation of $D S$. DS patients with lower $\mathrm{VB}_{12}$ levels demonstrated higher levels of overall DNA methylation $(2.51 \pm 1.13$ vs. $1.57 \pm 0.65$, respectively; $\mathrm{P}=0.031$ ), while $\mathrm{DS}$ patients with higher levels of Hcy had lower levels of overall DNA methylation $(1.30 \pm 0.24$ vs. $1.72 \pm 0.78$, respectively; $\mathrm{P}=0.021)$. However, no significant differences were identified in the level of overall DNA methylation between DS patients with different levels of FA (Table III).

\section{Discussion}

Down's syndrome is a chromosomal disorder caused by the presence of three copies of chromosome 21 (15). The increase in the dosage of genes located on this chromosome results in an altered profile of metabolites involved in the folate pathway. These genetic abnormalities can result in folate and $\mathrm{VB}_{12}$ malnutrition, which in turn affects relevant biochemical pathways. Such alterations are attributed to the disturbance of the highly integrated network of metabolic pathways in DS subjects. As a result, cellular dysfunction occurs, which may lead to epigenetic modifications and the consequent unique pathogenesis of Down's syndrome (16).

Individuals with trisomy 21 present with abnormalities in the methionine cycle, which can be attributed to the additional copy of the cystathionine $\beta$-synthase $(\mathrm{C} \beta \mathrm{S})$ gene located on chromosome $21(16,17)$. The $\mathrm{C} \beta \mathrm{S}$ gene encodes an enzyme that catalyzes the condensation of Hcy to form cystathionine in the Hcy transsulfuration pathway, and C $\beta S$ overexpression leads to an increase in the activity of this pathway. Hcy transsulfuration pathway hyperactivity concomitantly causes an accumulation of 5-methyltetrahydrofolate (5-MTHF) and a reduction in the conversion of 5-MTHF to tetrahydrofolate, which is the metabolically active form of folate required for de novo synthesis of nucleotides necessary for RNA and DNA synthesis. Consequently, a functional folate deficiency can be observed even in the presence of normal or elevated serum folate concentrations (16). The data in the present study are in agreement with this theory. In the present study, with increasing age, serum folate levels decreased significantly, as shown in DS patients in the $\geq 6$ year-old group, which had the lowest FA levels. Therefore, the FA serum level is not an accurate reflection of the FA nutritional status in DS patients. In addition, as DS patients age, the degree of folate deficiency becomes more apparent.

Vitamin $B_{12}$ is a cofactor that is important for the conversion of Hcy to methionine. Our data revealed that DS patients exhibited lower serum vitamin $B_{12}$ levels compared with $\mathrm{HCs}$, which are consistent with the results from the study by Meguid et al (18). In addition, the present data demonstrated that the serum levels of $\mathrm{FA}$ and $\mathrm{VB}_{12}$ decreased with increasing age in DS patients, with the lowest levels observed in the $\geq 6$ year-old group. Together, these results indicate that DS patients not only show abnormalities in the one-carbon unit 
Table II. Comparison of FA, $\mathrm{VB}_{12}$, Hcy and overall DNA methylation levels in DS patients and HCs.

\begin{tabular}{lccc}
\hline Detected indicators & DS & HC & P-value \\
\hline FA $(\mathrm{ng} / \mathrm{ml})$ & $7.06 \pm 3.74$ & $7.46 \pm 3.91$ & 0.675 \\
$\mathrm{VB}_{12}(\mathrm{pmol} / \mathrm{l})$ & $342.55 \pm 193.01$ & $447.38 \pm 130.70$ & $0.008^{\mathrm{a}}$ \\
$\mathrm{Hcy}(\mu \mathrm{mol} / \mathrm{l})$ & $8.85(6.93-13.3)$ & $5.20(4.70-5.88)$ & $0.000^{\mathrm{a}}$ \\
DNA methylation $(5-\mathrm{mC}, \%)$ & $1.65 \pm 0.73$ & $1.41 \pm 0.53$ & 0.107
\end{tabular}

Hcy is expressed as the median (interquartile interval). Other variables are presented as the mean \pm standard deviation. ${ }^{\mathrm{a}} \mathrm{P}<0.05$, DS patients vs. HC. DS, Down's syndrome; HC, healthy control; FA, folic acid; $\mathrm{VB}_{12}$, vitamin $\mathrm{B}_{12}$; Hcy, homocysteine; 5-mC, 5-methylcytosine.

Table III. DNA methylation level in different concentrations of FA, VB ${ }_{12}$ and Hcy in DS children.

\begin{tabular}{lc}
\hline Detected indicators & Global DNA methylation level \\
\hline FA $(\mathrm{ng} / \mathrm{ml})$ & \\
$>5.38$ & $1.45 \pm 0.54$ \\
$\leq 5.38$ & $1.82 \pm 0.96$ \\
$\mathrm{VB}_{12}(\mathrm{pmol} / \mathrm{l})$ & \\
$>156$ & $1.57 \pm 0.65$ \\
$\leq 156$ & $2.51 \pm 1.13$ \\
$\mathrm{Hcy}(\mu \mathrm{mol} / \mathrm{l})$ & \\
$<15$ & $1.72 \pm 0.78$ \\
$\geq 15$ & $1.30 \pm 0.24$ \\
\hline
\end{tabular}

Variables are presented as the mean \pm standard deviation. ${ }^{\mathrm{a}} \mathrm{P}<0.05$, the $\mathrm{VB}_{12}$ concentration $>156 \mathrm{pmol} / 1$ group vs. the $\mathrm{VB}_{12}$ concentration $\leq 156 \mathrm{pmol} / 1$ group. ${ }^{\mathrm{b}} \mathrm{P}<0.05$, the Hcy concentration $<15 \mu \mathrm{mol} / 1$ group vs. the Hcy concentration $\geq 15 \mu \mathrm{mol} / 1$ group. Global DNA methylation, 5-mC (\%). DS, Down's syndrome; FA, folic acid; $\mathrm{VB}_{12}$, vitamin $\mathrm{B}_{12} ;$ Hcy, homocysteine.

A

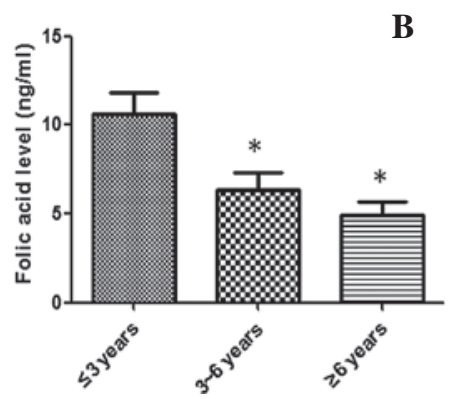

B

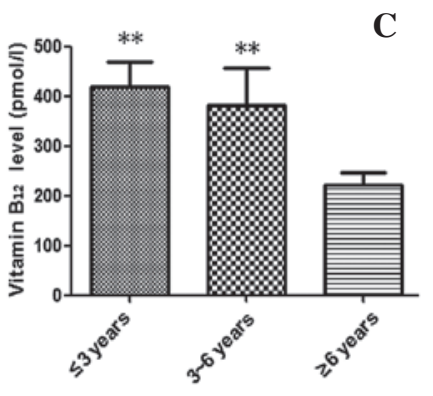

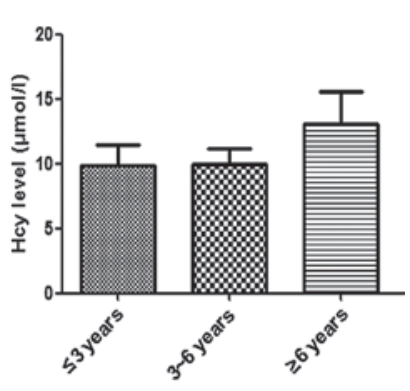

Figure 2. Comparison of (A) FA, (B) $\mathrm{VB}_{12}$ and (C) Hcy levels in different age groups of DS children. Variables are presented as the mean \pm standard deviation. ${ }^{*} \mathrm{P}<0.05$ vs. the $\leq 3$ years group; ${ }^{* *} \mathrm{P}<0.05$ vs. the $\geq 6$ years group. DS, Down's syndrome; FA, folic acid; $\mathrm{VB}_{12}$, vitamin $\mathrm{B}_{12} ; \mathrm{H}$ cy, homocysteine.

cycle, but that the consequences of these abnormalities tend to worsen with age.

Hcy has direct neurotoxicity. In regards to the plasma level of Hcy in DS patients there is certain controversy. Meguid et al (18) reported that DS children had low serum Hcy levels, which is in agreement with the findings of Varga et al (19). However, the present study demonstrated that DS patients had higher levels of Hcy than HCs, which is consistent with the results of Licastro et al (20). It is possible that DS patients may have polymorphisms or altered 5,10-methylene-tetrahydrofolate reductase (MTHFR) activity or expression, and that methionine synthase reductase (MTRR) may contribute to abnormal levels of Hcy $(21,22)$. MTHFR catalyzes the conversion of 5,10-methylenetetrahydrofolate to 5-methyltetrahydrofolate, which is the methyl donor in the remethylation of Hcy to methionine driven by methionine synthase (MS). This in turn is maintained in its active form by MTRR. In addition, MS is a vitamin $B_{12}$-dependent enzyme. Therefore, reduced MTHFR activity results in an increased demand for FA in order to maintain normal Hcy levels for its remethylation into methionine (23). A previous study demonstrated that Hcy concentrations can be affected by other genetic polymorphisms, including the TCN2 776GG and BHMT 742AA genotypes, which are associated with reduced Hcy concentrations (24). In addition to genetic polymorphisms and alterations in gene expression, the level of $\mathrm{FA}$ and/or $\mathrm{VB}_{12}$ 
also affects the Hcy level. Nutritional intervention with high doses of $\mathrm{FA}$ and $\mathrm{VB}_{12}$ in patients with homocysteinemia has proven to be a successful clinical approach to restore normal Hcy levels and folate levels $(16,25,26)$. These findings indicate that plasma Hcy is affected by genotype and nutritional status. However, since these studies included subjects with different ethnicities, ages, genetic polymorphisms and nutritional statuses, drawing broad conclusions regarding the effects of Hcy concentration in DS patients may be difficult.

The folate pathway is important in the interactions between nutrition, epigenomics and gene expression. It also has an effect on DNA methylation, which is one of a group of epigenetic modifications to the genome that affect the expression of specific genes without modifying the sequence of the genome itself. Methyl groups are added to $\mathrm{CpG}$ dinucleotides, and these modifications in turn recruit chromatin remodeling complexes that can alter the structure of the surrounding chromatin and either increase or decrease the availability of the gene for expression. Although global DNA methylation levels were higher in DS patients in the present study, the differences were not statistically significant, which is in contrast to the results obtained by Pogribna et al (16). These contrasting results may be due to age and Hcy level differences in the subjects included in the two studies. However, our data suggest that patients with $\mathrm{VB}_{12}$ deficiency show DNA hypermethylation, while patients with hyperhomocysteinemia have DNA hypomethylation. $\mathrm{VB}_{12}$ is required for the conversion of homocysteine to methionine and for the formation of SAM. SAM is involved in biological methylation reactions and allows for the generation of S-adenosylhomocysteine ( $\mathrm{SAH}$ ), which subsequently forms Hcy. SAH is a potent inhibitor of the activity of DNMTs through the product inhibition pathway and can cause genome hypomethylation (27). As such, increased Hcy levels may promote $\mathrm{SAH}$ accumulation, which actively inhibits SAM-dependent methyltransferases, including DNMTs, which culminates in DNA hypomethylation. Conversely, decreased $\mathrm{VB}_{12}$ reduces SAH levels, which eventually leads to DNA hypermethylation. Previous studies have demonstrated that alterations in DNA methylation are associated with normal aging and AD (28-30). In addition, the promoter for the gene encoding amyloid precursor protein (APP), which is implicated in the development of AD, is specifically hypomethylated in brain tissues from AD patients (31).

Furthermore, APP is located on chromosome 21 (32). Taken together, these results suggest that alterations in DNA methylation of relevant genes may be involved in the neuropathological alterations observed in DS patients, although additional studies are required to determine the specific methylation sites that are associated with brain aging in DS. In addition, evaluation of changes in epigenetic markers may be useful for identifying biomarkers of brain aging in DS patients.

In conclusion, these data demonstrated that DS patients exhibit abnormalities in the one-carbon unit cycle that tend to worsen with increasing age. DS patients with $\mathrm{VB}_{12}$ deficiency demonstrated DNA hypermethylation, while those with hyperhomocysteinemia had DNA hypomethylation. It was demonstrated that the genetic abnormalities occurring in DS superimpose with $\mathrm{VB}_{12}$ malnutrition in these patients, resulting in the alteration of overall DNA methylation levels that can cause biochemical dysfunction, which in turn may lead to nervous system degeneration. However, further studies are required to identify the specific methylation sites that are associated with brain degeneration in DS patients. Evaluation of alterations in epigenetic markers may be useful for identifying biomarkers of brain degeneration that can occur in DS patients.

\section{Acknowledgements}

The authors would like to thank the collaborators and participants who contributed to the research described here. In particular the authors would like to thank the subjects and their guardians who were involved the study. This study was supported by the Ministry of Education Key Laboratory of Child Development and Disorders, The Key Laboratory of Pediatrics in Chongqing and Chongqing International Science and the Technology Cooperation Center for Child Development and Disorders. Professor Tingyu Li was partially supported by the Natural Science Foundation of China (grant no. 81161120498) and Dr Cui Song was partially supported by the Chongqing Science and Technology Commission, Chongqing China (grant no. cstc2013yykfA110011).

\section{References}

1. Galdzicki Z, Siarey R, Pearce R, Stoll J and Rapoport SI: On the cause of mental retardation in Down syndrome: Extrapolation from full and segmental trisomy 16 mouse models. Brain Res Brain Res Rev 35: 115-145, 2001.

2. Parker SE, Mai CT, Canfield MA, Rickard R, Wang Y, Meyer RE, Anderson P, Mason CA, Collins JS, Kirby RS, et al: Updated national birth prevalence estimates for selected birth defects in the united states, 2004-2006. Birth Defects Res A Clin Mol Teratol 88: 1008-1016, 2010.

3. Zigman WB: Atypical aging in Down syndrome. Dev Disabil Res Rev 18: 51-67, 2013.

4. Lott IT, Doran E, Nguyen VQ, Tournay A, Head E and Gillen DL: Down syndrome and dementia: A randomized, controlled trial of antioxidant supplementation. Am J Med Genet A 155A: 1939-1948, 2011.

5. Bhargava S and Tyagi SC: Nutriepigenetic regulation by folate-homocysteine-methionine axis: A review. Mol Cell Biochem 387: 55-61, 2014.

6. Nazki FH, Sameer AS and Ganaie BA: Folate: Metabolism, genes, polymorphisms and the associated diseases. Gene 533: 11-20, 2014.

7. Jaenisch R and Bird A: Epigenetic regulation of gene expression How the genome integrates intrinsic and environmental signals. Nat Genet 33 (Suppl): S245-S254, 2003.

8. Cedar $\mathrm{H}$ and Bergman Y: Linking DNA methylation and histone modification: Patterns and paradigms. Nat Rev Genet 10: 295-304, 2009.

9. Zhang L, Ren A, Li Z, Hao L, Tian Y and Li Z: Folate concentrations and folic acid supplementation among women in their first trimester of pregnancy in a rural area with a high prevalence of neural tube defects in Shanxi, China. Birth Defects Res A Clin Mol Teratol 76: 461-466, 2006.

10. Jones MJ, FarréP,McEwen LM, Macisaac JL, Watt K, Neumann SM, Emberly E, Cynader MS, Virji-Babul N and Kobor MS: Distinct DNA methylation patterns of cognitive impairment and trisomy 21 in Down syndrome. BMC Med Genomics 6: 58, 2013.

11. Measurement and use of total plasma homocysteine. American society of human genetics/american college of medical genetics test and technology transfer committee working group. Am J Hum Genet 63: 1541-1543, 1998 .

12. Wiley KL, Treadwell E, Manigaba K, Word B and Lyn-Cook BD: Ethnic differences in DNA methyltransferases expression in patients with systemic lupus erythematosus. J Clin Immunol 33: 342-348, 2013.

13. Murphy TM, Mullins N, Ryan M, Foster T, Kelly C, McClelland R, O'Grady J, Corcoran E, Brady J, Reilly M, et al: Genetic variation in DNMT3B and increased global DNA methylation is associated with suicide attempts in psychiatric patients. Genes Brain Behav 12: 125-132, 2013. 
14. Li W and Liu M: Distribution of 5-hydroxymethylcytosine in different human tissues. J Nucleic Acids 2011: 870726, 2011.

15. Mégarbané A, Ravel A, Mircher C, Sturtz F, Grattau Y, Rethoré MO, Delabar JM and Mobley WC: The 50th anniversary of the discovery of trisomy 21: The past, present, and future of research and treatment of Down syndrome. Genet Med 11: 611-616, 2009.

16. Pogribna M, Melnyk S, Pogribny I, Chango A, Yi P and James SJ: Homocysteine metabolism in children with Down syndrome: In vitro modulation. Am J Hum Genet 69: 88-95, 2001.

17. Coppus AW, Fekkes D, Verhoeven WM, Tuinier S, Egger JI and van Duijn CM: Plasma amino acids and neopterin in healthy persons with Down's syndrome. J Neural Transm 114: 1041-1045, 2007.

18. Meguid NA, Dardir AA, El-Sayed EM, Ahmed HH, Hashish AF and Ezzat A: Homocysteine and oxidative stress in Egyptian children with Down syndrome. Clin Biochem 43: 963-967, 2010.

19. Varga P, V Oláh A and Oláh E: Biochemical alterations in patients with Down syndrome. Orv Hetil 149: 1203-1213, 2008 (In Hungarian).

20. Licastro F, Marocchi A, Penco S, Porcellini E, Lio D, Dogliotti G and Corsi MM: Does Down's syndrome support the homocysteine theory of atherogenesis? Experience in elderly subjects with trisomy 21. Arch Gerontol Geriatr 43: 381-387, 2006.

21. Scala I, Granese B, Sellitto M, Salomè S, Sammartino A, Pepe A, Mastroiacovo P, Sebastio G and Andria G: Analysis of seven maternal polymorphisms of genes involved in homocysteine/folate metabolism and risk of Down syndrome offspring. Genet Med 8: 409-416, 2006.

22. Coppedè F, Migheli F, Bargagna S, Siciliano G, Antonucci I, Stuppia L, Palka G and Migliore L: Association of maternal polymorphisms in folate metabolizing genes with chromosome damage and risk of Down syndrome offspring. Neurosci Lett 449: 15-19, 2009.

23. Das UN: Folic acid and polyunsaturated fatty acids improve cognitive function and prevent depression, dementia and Alzheimer's disease-but how and why? Prostaglandins Leukot Essent Fatty Acids 78: 11-19, 2008.
24. Biselli JM, Zampieri BL, Goloni-Bertollo EM, Haddad R, Fonseca MF, Eberlin MN, Vannucchi H, Carvalho VM and Pavarino EC: Genetic polymorphisms modulate the folate metabolism of Brazilian individuals with Down syndrome. Mol Biol Rep 39: 9277-9284, 2012.

25. Lowering blood homocysteine with folic acid based supplements: Meta-analysis of randomised trials. Homocysteine lowering trialists' collaboration. BMJ 316: 894-898, 1998

26. Fillon-Emery N, Chango A, Mircher C, Barbé F, Bléhaut H, Herbeth B, Rosenblatt DS, Réthoré MO, Lambert D and Nicolas JP: Homocysteine concentrations in adults with trisomy 21: Effect of B vitamins and genetic polymorphisms. Am J Clin Nutr 80: 1551-1557, 2004.

27. Lee WJ and Zhu BT: Inhibition of DNA methylation by caffeic acid and chlorogenic acid, two common catechol-containing coffee polyphenols. Carcinogenesis 27: 269-277, 2006.

28. Hannum G, Guinney J, Zhao L, Zhang L, Hughes G, Sadda S, Klotzle B, Bibikova M, Fan JB, Gao Y, et al: Genome-wide methylation profiles reveal quantitative views of human aging rates. Mol Cell 49: 359-367, 2013

29. Liu L, van Groen T, Kadish I and Tollefsbol TO: DNA methylation impacts on learning and memory in aging. Neurobiol Aging 30: 549-560, 2009.

30. Bakulski KM, Dolinoy DC, Sartor MA, Paulson HL, Konen JR, Lieberman AP, Albin RL, Hu H and Rozek LS: Genome-wide DNA methylation differences between late-onset Alzheimer's disease and cognitively normal controls in human frontal cortex. J Alzheimers Dis 29: 571-588, 2012.

31. Chouliaras L, Mastroeni D, Delvaux E, Grover A, Kenis G, Hof PR, Steinbusch HW, Coleman PD, Rutten BP and van den Hove DL: Consistent decrease in global DNA methylation and hydroxymethylation in the hippocampus of Alzheimer's disease patients. Neurobiol Aging 34: 2091-2099, 2013.

32. Tanzi RE, McClatchey AI, Lamperti ED, Villa-Komaroff L, Gusella JF and Neve RL: Protease inhibitor domain encoded by an amyloid protein precursor mRNA associated with Alzheimer's disease. Nature 331: 528-530, 1988. 